\title{
As concepções de ideologia em três gerações de pensadores da Teoria Crítica
}

\author{
The conception of ideology in three generations of \\ critical theory thinkers
}

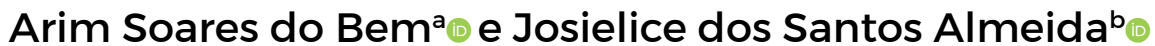

\begin{abstract}
Resumo O presente artigo discute o conceito de ideologia entre os principais autores de três gerações da Teoria Crítica vinculados à Escola de Frankfurt: Horkheimer, Adorno, Habermas e Honneth. A partir de uma seleção de obras significativas desses autores, demonstra-se o caráter polêmico e polissêmico do conceito de ideologia e procura-se dar visibilidade às especificidades dos diferentes sistemas teóricos que orientam representações singulares no âmbito desta tradição teórica.
\end{abstract}

Palavras-chave Ideologia. Crítica da ideologia. Teoria Crítica. Escola de Frankfurt.

Abstract This article discusses the concept of ideology among the main authors of three generations of Critical Theory linked to the Frankfurt School: Horkheimer, Adorno, Habermas and Honneth. From a selection of significant works by these authors, the polemic and polysemic character of the concept of ideology is demonstrated and, at the same time, weseek to give visibility to the specificities of the different theoretical systems that guide singular representations within the scope of this theoretical tradition. Keywords Ideology. Critique of ideology. Critical Theory. Frankfurt School.

\section{INTRODUÇÃO}

O objetivo deste artigo é discutir o conceito de ideologia nas diferentes versões da Teoria Crítica, das origens à atualidade e reconstruir as especificidades de seus usos em uma seleção de obras significativas desta tradição intelectual. Desenvolve-se uma reflexão acerca do modo como a ideologia demonstra ser uma temática

a Arim Soares do Bem é Dr. Phil. em Sociologia pela Freie Universität Berlin (1997), Mestre em Ciências da Comunicação pela Escola de Comunicações e Artes da Universidade de São Paulo USP, realizou pós-doutorados na Universidade Federal do Rio de Janeiro - UFRJ (2013-2014) e atua no Programa de Pós-Graduação em Sociologia da Universidade Federal de Alagoas - UFAL e nos cursos de Bacharelado e Licenciatura em Ciências Sociais do Instituto de Ciências Sociais da mesma Universidade. E-mail: mebsores@gmail.com

b Josielice dos Santos Almeida é Mestre em Sociologia (2021) no Programa de Pós-Graduação em Sociologia do Instituto de Ciências Sociais da Universidade Federal de Alagoas -UFAL e graduada em Licenciatura em Ciências Sociais no mesmo Instituto e Universidade (2018). E-mail: josielicealmeida@hotmail.com 
recorrente na Teoria Crítica frankfurtiana, uma vez que se apresenta como central na produção dos autores abordados.

$\mathrm{O}$ artigo está estruturado em quatro momentos. No primeiro deles leva-se em consideração as mudanças teórico-filosóficas em três gerações de pensadores como Horkheimer, Adorno, Habermas e Honneth. Nos três momentos seguintes dá-se continuidade à reflexão sobre os processos de reconfiguração da crítica da ideologia, reconstruindo os seus principais aspectos teóricos em obras significativas dos autores mencionados. Em Adorno e Horkheimer, parte-se da Dialética do Esclarecimento [1947], obra escrita em conjunto a partir de 1942 no exílio estadunidense e nos anos finais da Segunda Guerra Mundial. Nessa produção, os autores, que intencionavam elaborar uma crítica global da ideologia considerando-a não só um produto da consciência, mas também um modo de constituição dos sujeitos (Cf. Wiggershaus, 2002, p. 344), contribuem para a crítica da ideologia a partir da reflexão sobre a estrutura e o modo de funcionamento da indústria cultural, que aprofundaria ainda mais a degradação da razão esclarecida em razão instrumental. A indústria cultural, como estava configurada no contexto histórico de produção da obra, era por eles considerada como tendo um caráter regressivo e, por esta razão, enredada na reprodução sem precedentes da razão instrumental e na consolidação da lógica da ação racional com relação a fins, no exercício de controles sociais cada vez mais totalizadores, assim como na desmobilização dos potenciais emancipatórios de indivíduos crescentemente atomizados.

Na sequência, a partir do ensaio Técnica e ciência como "ideologia” [1968], de Habermas, demonstra-se como este pensador, ao contestar concepções da primeira geração da Teoria Crítica, posiciona-se em oposição ao relevo colocado por estes na razão instrumental. Habermas defende uma racionalidade que seria proveniente da ação comunicativa dos sujeitos, estabelecendo uma "virada linguística", a partir da qual a problemática da racionalidade passa a ser tratada na perspectiva dos próprios atores no complexo jogo das mediações intersubjetivas. Ao explicitar a dificuldade da primeira geração em diferenciar entre o mundo sistêmico e o mundo da vida (Lebenswelt), que, afinal, é por ele mesmo construída, Habermas reformula o conceito de racionalização e, com isso, dirige críticas tanto a Weber como a Marcuse, a quem o ensaio de 1968 é dedicado. No novo quadro categorial proposto, Habermas distingue entre o trabalho e a interação, fazendo da interação a esfera no interior da qual se desenvolve a ação comunicativa simbolicamente mediada.

A ideologia é tratada neste ensaio de Habermas (2014) como tendo a função de manter o status quo através de políticas compensatórias administradas pelo Estado do Bem Estar Social, ao preço da desmobilização e despolitização dos 
trabalhadores. As mudanças estruturais nas formas de mediação entre o Estado e a sociedade, no Pós-Guerra, teriam alterado o modelo clássico de antagonismos e conflitos entre dominadores e dominados e, consequentemente, transformado a ideologia em uma força produtiva inscrita no próprio processo tecnológico, que tenderia a fortalecer a consciência tecnocrática dos indivíduos e a afetar drasticamente os modos de organização de suas vidas coletivas.

Depois de apontados os aspectos mais significativos da crítica da ideologia em Adorno, Horkheimer e Habermas, é dada continuidade à exposição a partir das considerações teóricas de Honneth, autor considerado um importante representante da terceira geração de teóricos críticos vinculados ao Instituto de Pesquisa Social. O conceito central de sua teoria é o reconhecimento intersubjetivo, desenvolvido por ele em várias etapas de suas elaborações teóricas, no quadro abrangente de apropriação e integração das contribuições de pensadores situados nos campos disciplinares da filosofia, da psicologia social, da psicanálise e da teoria sociológica. Honneth, em virtude de focar sua construção teórica nos ideais normativos e nos pressupostos do reconhecimento intersubjetivo, à exceção de seus predecessores, aborda a ideologia de modo pouco sistemático e tende a considerá-la expressão de patologias sociais, como se depreende do trabalho de investigação de Almeida (2021), que também situa esta problemática no contexto da reflexão deste autor sobre a reificação e as contradições paradoxais.

\section{TEORIA CRÍTICA E IDEOLOGIA}

A Teoria Crítica é conhecida como uma tradição teórica que emergiu nos anos 1930 com Max Horkheimer, que esteve à frente do Instituto de Pesquisa Social como diretor desde o início da década. O círculo teórico vinculado ao Instituto reúne pensadores como Horkheimer, Adorno, Marcuse, Walter Benjamin, Fromm, Löwenthal, Pollock, Neumann e Kirchheimer como os mais relevantes pensadores da primeira geração ligada à história do Instituto (os três primeiros aparecem com maior frequência na vida pública do Instituto). Outros estudiosos deram continuidade e atualização a essa teoria: Habermas, por exemplo, é considerado um dos mais expressivos representantes da segunda geração; e, atualmente, Honneth apresenta-se como um importante expoente da terceira geração. Cabe considerar que o que define a natureza específica das "gerações" de pensadores do Instituto de Pesquisa Social é mais o envolvimento temático e reflexivo desses autores em relação às pautas de investigação em suas várias fases de concepção e execução do que propriamente a existência de um consenso que permitiria situá-los em torno de paradigmas teóricos unitários. Muitos desses pesquisadores operaram, 
por exemplo, a partir de posições extremamente distintas sobre temas comuns (Cf. Wiggershaus, 2002, p. 35).

No que concerne à crítica da ideologia desenvolvida no âmbito da Teoria Crítica, Sheyla Benhabib (1996) afirma que os frankfurtianos, no desenvolvimento de suas abordagens, "alteraram o próprio sentido da crítica social marxista e da crítica das ideologias” (Benhabib, 1996, p. 72). Salienta-se que esta tradição intelectual ganha forma como uma nova teoria a partir do ensaio de Horkheimer, Teoria tradicional e teoria crítica, publicado em 1937.

O contexto político e histórico influenciou fundamentalmente a primeira geração de autores da Teoria Crítica, cuja maioria dos membros exilou-se nos Estados Unidos após a ascensão do nacional-socialismo na Alemanha. Se partimos das considerações de Benhabib (1996), que chama a atenção para as mudanças e os acontecimentos históricos que levaram essa teoria a repensar a si mesma, podemos compreender que é na produção da década de 1930 que ganha forma a fase inicial da primeira Teoria Crítica. Nesta direção, vemos que a evolução do programa de pesquisas do Instituto de Pesquisa Social de Frankfurt divide-se em três fases distintas: a fase do "materialismo interdisciplinar" (1932-1937); a abordagem da "teoria crítica" (1937-1940); e a "crítica da razão instrumental" (1940-1945). Com essas fases redefiniram-se as relações entre a teoria e a prática e conhecimento e poder; e foram também reconceituadas a interdependência entre filosofia e ciência e a teoria crítica e o marxismo (Benhabib, 1996, p. 72).

Para Chiarello (2001, p. 239), os fundamentos da Teoria Crítica da década de 1930 se diferenciam daqueles desenvolvidos depois da década de 1940: a teoria da década de 1930 ter-se-ia ocupado principalmente da "denúncia da opressão ideológica vigente na sociedade burguesa" e, depois da década de 1940, da análise da sociedade capitalista "totalmente" administrada por uma totalidade burocrática, vista por Adorno e Horkheimer como uma ruptura do processo civilizador. Por conseguinte, a teoria crítica ver-se-ia impossibilitada de fazer uma crítica imanente da sociedade nos moldes da crítica da economia política de Marx, que havia sido adotada por Horkheimer nos anos 1930 e abandonada a partir dos anos 1940.

Habermas, ao tentar superar o horizonte "pessimista" das obras de seus predecessores, rompe com a crítica totalizante da razão instrumental, a partir de uma concepção intersubjetiva da razão, como já salientamos em relação ao ensaio de 1968, Técnica e ciência como "ideologia" - uma obra embrionária de sua teoria da comunicação. Habermas repensa o conceito weberiano de "racionalização" e inclui, além do trabalho, o conceito de interação no contexto histórico no qual o ensaio foi produzido [1968], que ele identifica como favorecendo o fortalecimento da 
consciência tecnocrática. A ideologia, para ele, passaria a cumprir funções distintas daquelas típicas do período clássico, substituindo as legitimações tradicionais da dominação e mantendo latentes as oposições de classe, mas dissimulando-as, no entanto, através do emprego de uma fachada distributiva compensatória característica do capitalismo tardio, regulado pelo Estado (Habermas, 2014, p. 114). Considerando-se a expansão dos subsistemas de ação racional com relação a fins, ao lado do progresso técnico-científico e da crescente despolitização da esfera pública pelos meios de comunicação de massa, altera-se substancialmente o quadro institucional e a colonização do mundo da vida pelo mundo sistêmico torna-se uma ameaça tangível. Como veremos no tópico específico sobre Habermas, é somente através de um processo de comunicação livre de distorções que se pode encontrar fontes de racionalidade opostas a um sistema funcional de poder e, com isso, conter o bloqueio estrutural aos potenciais emancipatórios.

Ao incorporar às suas elaborações teóricas o conceito de interação - supostamente negligenciado por Marx -, Habermas abre horizontes para a expansão da Teoria Crítica, que se desdobra na Teoria do reconhecimento de Axel Honneth. A partir de fontes que remontam a Kant, Fichte, Schelling e em especial a Hegel, mas também a G. Mead, à psicanálise de Winnicott e a vários representantes das tradições pregressas da tradição da Escola de Frankfurt, a Teoria do reconhecimento honnethiana em quase três décadas vem alcançando relevante posição nas discussões contemporâneas da Filosofia Política e Social.

Com sua Teoria do reconhecimento - diga-se de passagem: teoria em permanente processo de expansão e reavaliação, como faz questão de salientar Soares do Bem (2020) em seu recente artigo para advertir contra o perigo da essencialização -, Honneth busca extrair dos conflitos e de suas configurações sociais e institucionais as bases normativas com as quais se evidenciam as lógicas e os mecanismos modernos do poder - e também da resistência a eles. Ao dimensionar o conflito como o fundamento social da Teoria Crítica, a Teoria do reconhecimento constitui-se como "uma teoria social mais próxima das ciências humanas e de suas aplicações empíricas” (Nobre, 2009, p. 17-19). Com uma versãoformalmente postulada enquanto ancorada numa perspectiva pós-metafísica da teoria hegeliana do reconhecimento, o autor fornece o quadro teórico para a análise da gramática moral dos conflitos sociais (Sinnerbrink, 2017, p. 173) e promete uma reiterada renovação da Teoria Crítica.

Ao contrário das abordagens das gerações pregressas da Teoria Crítica, que desenvolveram críticas sistemáticas da ideologia a partir de necessidades imanentes as suas produções teóricas, Honneth, após confrontar-se com críticas 
externas às suas obras, viu-se premido a responder a vários questionamentos e, entre estes, se seria possível conceber formas de reconhecimento e de valorização de sujeitos que poderiam, paradoxalmente, contribuir para a sua reiterada opressão.

\section{ADORNO E HORKHEIMER: O ECLIPSE DO ESCLARECIMENTO E A CRÍTICA DA RAZÃO INSTRUMENTAL}

Adorno e Horkheimer são os precursores e os representantes mais significativos da primeira geração de pensadores da Teoria Crítica. Em conjunto, produziram a obra Dialética do Esclarecimento, escrita no fervor da Segunda Guerra Mundial e publicada em 1947, em que pese a divisão da autoria dos capítulos (Cf. Chiarello, 2001, p. 145-46). Nessa obra, os autores desenvolveram uma instigante reflexão sobre o fracasso do ideal iluminista de razão, que teria se degradado, apesar de sua intenção imanente de desmistificar o mundo, em mera razão instrumental.

A partir de uma abordagem incisivamente crítica da sociedade de sua época, os autores demonstraram como a própria razão iluminista, que garantiu as revoluções instauradoras da ascensão da burguesia ao poder político no século XVIII, sucumbe ao descrédito da mitologia que se supunha encerrada no passado. Desse modo, a razão iluminista passaria a ser compreendida como reiterada mitologia, caracterizada por uma cega "fé no progresso técnico, na organização 'racional' da sociedade e na dominação da natureza" (Sinnerbrink, 2017, p. 126). O primeiro impasse com o qual se ocuparam no âmbito de suas reflexões foi com a investigação sobre o processo de autodestruição do esclarecimento; e compreender "por que a humanidade, em vez de entrar em um estado verdadeiramente humano, estaria se afundando em uma nova espécie de barbárie" (Adorno, Horkheimer, 1985, p. 11) foi o primeiro impulso que moveu os autores a desenvolverem sua análise na Dialética do Esclarecimento.

Para Adorno e Horkheimer (1985), o progresso do pensamento objetivava primordialmente livrar os sujeitos do medo e dotá-los da posição de "senhores"; o esclarecimento atuaria, portanto, como um desencantamento do mundo, como desvelador do mito e da imaginação, substituindo-os, assim, pelo saber. No entanto, a sociedade industrializada ver-se-ia presa de um paradoxo bastante surpreendente: o total esclarecimento teria dado espaço a uma calamidade triunfal. Neste sentido, os autores afirmaram que

O progresso da sociedade industrial, que deveria ter eliminado como por encanto a lei da pauperização que ela própria produzira, acaba por destruir a ideia pela qual o todo se justificava: o homem enquanto pessoa, enquanto portador de 
razão. A dialética do esclarecimento transforma-se objetivamente em loucura (Adorno, Horkheimer, 1985, p. 168).

Para Adorno e Horkheimer, com o surgimento da indústria cultural o esclarecimento teria se degradado à condição de uma ideologia com características regressivas. Os autores denunciaram o funcionamento dos meios de comunicação de massa e da indústria do entretenimento "como um sistema que não só assegurou a sobrevivência do capitalismo como continua exercendo função essencial em sua preservação, reprodução e renovação" (Konder, 2002, p. 82), uma vez que estes cumpririam, ao lado da ciência, a função ideológica de estender as regras do mundo do trabalho ao espaço de um lazer vivenciado de forma cada vez menos autônoma e de adaptar os espectadores a uma "sequência automatizada de operações padronizadas" (Adorno, Horkheimer, 1985, p. 128). A Dialética do Esclarecimento é, portanto, expressão de uma formulação teórica negativa sobre o desmantelamento daquela visão histórica otimista, que marcara não só as utopias do século XIX mas também a própria concepção da Teoria Crítica dos anos 1930 como uma via que levaria à redenção.

Joan Alway (1995, p. 31), em sua obra sobre as possibilidades políticas da Teoria Crítica, afirma que a Dialética do Esclarecimento não abre "rodovias" para a reconciliação entre o mundo objetivo e o mundo subjetivo, mas concebe apenas frágeis caminhos para pedestres. Enquanto a razão objetiva pressupõe a assimilação desta ao pensamento, a razão subjetiva considera que a razão é assimilada enquanto um instrumento da autoconservação. Esses dois conceitos de razão são de extrema importância para a compreensão da Dialética do Esclarecimento e a perpassam de todos os seus ângulos e em todas as suas dimensões, embora sem serem explicitados. Como afirma Wiggershaus (2002, p. 378), as posições dos autores sobre esses dois conceitos são reveladas mais por alusão do que por enunciação, fato este que - acrescentamos - pode ter provocado interpretações equivocadas sobre essa obra.

Ao se distanciar da natureza ao longo da história, a humanidade tê-la-ia transformado em objeto a ser manipulado e controlado segundo os seus interesses. Ao distanciar-se da natureza, o homem aliena-se da própria natureza e a luta para dominá-la exteriormente transforma-se em luta interna, que leva à distorção de suas paixões e instintos e à renúncia da experiência sensível, que se torna, assim, a chave explicativa da civilização. Várias passagens da Dialética do Esclarecimento referem-se às aventuras de Ulisses e à sua renúncia aos sentidos, que constitui para Adorno e Horkheimer a forma dominante de construção da identidade do Eu 
no mundo moderno (Adorno, Horkheimer, 1985, p. 45). A identidade do Eu todo poderoso, sustentada no pensamento racionalizador, que legitima a ciência como o único caminho para a verdade, reduz a multiplicidade do mundo a fórmulas calculistas que instituem a equivalência, a sistematização e a "posse" como grandezas comparáveis, intercambiáveis e mensuráveis: "no trajeto para a ciência moderna, os homens renunciaram ao sentido e substituíram o conceito pela fórmula, a causa pela regra e pela probabilidade" (Adorno, Horkheimer, 1985, p. 21). A oposição que o esclarecimento faz ao mito com o intento de banir todas as suas forças ocultas leva à hegemonia de uma racionalidade corrosiva, que submete as questões ligadas ao Ser ao império resoluto do Logos e à autonomização do pensamento em face dos objetos (Adorno, Horkheimer, 1985, p. 23-25).

Se, por um lado, a lógica da dominação se aninha como ideologia dentro do próprio pensamento e o coloca a serviço da reprodução da natureza não reconciliada, por outro, é ao próprio pensamento que cabe a tarefa de ir além da facticidade e abrir as vias para penetrar de modo reflexivo e ousado o objeto, de modo a impedir o seu total enrijecimento. Como se vê, a crítica intempestiva de Adorno e Horkheimer insurge-se contra a razão instrumental e não contra a razão em si, fato que nem sempre é considerado de modo adequado na recepção de seu pensamento. Por esta razão, Douglas Kellner (1989, p. 88, tradução própria) identifica "um resíduo de otimismo social” na Dialética do Esclarecimento, pois essa obra teria sido escrita com o objetivo de criticar o esclarecimento em nome do próprio esclarecimento. No entanto, há nesta obra poucas indicações de como as vias para um esclarecimento emancipatório deveriam ser construídas.

Por ocasião da produção da Dialética do Esclarecimento, o cinema e o rádio eram os veículos privilegiados através dos quais se manifestavam mais intensamente os processos acima descritos. O esclarecimento, desse modo, teria cedido lugar ao papel da indústria cultural, responsável por fomentar "conformidade e resignação entre os consumidores de bens culturais" (Soares do Bem, 2013, p. 91). A indústria cultural, portanto, não exerceria somente a função de meramente distrair ou entreter, mas um papel basilar enquanto uma "instituição de aperfeiçoamento moral" (Adorno, Horkheimer, 1985, p. 15), que, neste contexto, pode ser entendida como a pura e simples submissão à lógica da dominação.

Uma das críticas direcionadas a Adorno e a Horkheimer, e que repousa na problemática da agência, recai justamente sobre a projeção unilateral do "universo ideológico 'extremo' do fascismo nas estruturas inerentes diferentemente dos regimes capitalistas liberais" (Eagleton, 1997. p. 117). Ademais, como afirma 
Soares do Bem a propósito dos aspectos lacunares e criticáveis na Dialética do Esclarecimento,

\begin{abstract}
Se [...] os conceitos aí desenvolvidos podem ser úteis para caracterizar determinadas formas de coerção sobre os receptores, não permitem, no entanto, captar as suas diferentes estratégias para enfrentar essa mesma coerção, como o demonstram vários estudos que focalizam a recepção como complexo processo de mediação entre o texto e o contexto e que permitem, por decorrência, descobrir uma pulsante vitalidade e criatividade simbólica na vida cotidiana (Soares do Bem, 2013, p. 92, grifos nossos).
\end{abstract}

Saliente-se que a crítica de Soares do Bem (1988) a Adorno e Horkheimer decorreu de investigação empiricamente orientada, a partir da qual o autor acentuou, contra a tendência desses pensadores em verem vítimas passivas entregues às potências manipuladoras da indústria cultural, a existência de potenciais de resistência mesmo entre grupos de receptores socialmente vulneráveis, principalmente empregadas domésticas, na cidade de São Paulo, no final dos anos 1980. Ao colocar em relevo as práticas culturais vivas inscritas na cultura popular desses grupos, assim como as suas estratégias de sobrevivência, de construções identitárias e de organização política, o autor demonstrou a presença de um sistemático distanciamento - conceito brechtiano utilizado por ele em oposição à função catártica da tragédia - em relação aos conteúdos e repertórios estandardizados da indústria cultural unilateralmente considerados por Adorno e Horkheimer. Neste sentido, postulou que toda análise da recepção dos produtos da indústria cultural pelos setores populares precisa levar em consideração o modo como estes se articulam historicamente, se organizam e reagem às pressões ideológicas enquanto sujeitos em permanente processo de interação (Soares do Bem, 1992, p. 365, tradução própria) e, nesta mesma direção, afirmou ser premente o uso de métodos adequados para captar o movimento real dos sujeitos e, assim, tornar possível a interpelação do mito idealizado de seu imobilismo (Cf. Soares do Bem, 1986).

\title{
HABERMAS E A FUNDAÇÃO DA RAZÃO COMUNICATIVA
}

Habermas, no já referido ensaio Técnica e ciência como "Ideologia", de 1968, contesta concepções de Adorno e Horkheimer com relação ao que estes caracterizaram como a racionalidade das modernas sociedades. Em diálogo com os autores que o precederam, e com o objetivo de contribuir de forma "mais efetiva ao fortalecimento da 'razão comunicativa' e impor limites à expansão 'imperialista' 
da 'razão instrumental"', Habermas se viu na tarefa de forjar conceitos novos, "completando e corrigindo não só a ótica de Marx, mas também a de seus mestres Adorno e Horkheimer" (Konder, 2002, p. 132).

Habermas inicia seu ensaio com uma apresentação do conceito de racionalidade em Weber para seguir com apontamentos sobre a crítica de Marcuse a essa definição. Marcuse partiria da definição weberiana para apontar determinadas implicações ocultas no conceito weberiano de racionalização. Para ele, seriam inerentes à racionalização formas ocultas de dominação política. A racionalidade pensada nesses moldes não seria apenas "um processo de transformação das estruturas sociais de longo prazo, mas, ao mesmo tempo [...] a manutenção objetiva de uma dominação historicamente caduca por meio da invocação de imperativos técnicos" (Habermas, 2014, p. 80-81).

A hipótese de que o conceito de razão técnica seja ideologia, proposta por Marcuse, é, portanto, retomada por Habermas, mas com a enfática afirmação de que a técnica e a ciência se configurariam como ideologia. Tanto a ideia de uma nova técnica quanto a de uma nova ciência (postulada por Marcuse) não parece uma ideia defensável para Habermas. A revolução defendida por Marcuse, nestes moldes, teria o seu significado atenuado a uma mera transformação do quadro institucional, o que não alteraria a estrutura técnico-científica, mas só os valores que a orientam. O que haveria de novo na proposta de Marcuse se limita, na realidade, a uma diferente direção do progresso, que não chegaria a alterar o próprio padrão da racionalidade por ele criticada.

Tendo isto posto, Habermas desenvolve uma nova base tanto em relação à crítica que Marcuse dirige à Weber, quanto à tese de Marcuse da dupla função do processo técnico-científico, isto é, como força produtiva e como ideologia. Além disso, Habermas sinaliza também para uma lacuna no pensamento de Marx em relação ao conceito de interação (extraído da obra de juventude de Hegel), que teria permanecido oculto e indiferenciado no interior das esferas do trabalho por ele colocadas em evidência (Habermas, 2014, p. 23), as quais acentuariam apenas os efeitos instrumentais das relações econômicas sobre o conjunto da realidade social.

Habermas (2014) reformula e desdobra o conceito de "racionalidade" weberiano em racionalidade de baixo para cima e racionalidade de cima para baixo. Para ele, é sob uma pressão modernizante que se forma a infraestrutura da sociedade capitalista, impondo permanentemente uma adaptação de baixo para cima na medida em que se formam relações de troca de bens e de força de trabalho capitaneadas pela empresa capitalista. À pressão exercida a partir de baixo corresponde aquela que se impõe de cima para baixo e elas concorrem para fragilizar 
as formas tradicionais de legitimação, colocando a disponibilidade técnica em estreita interdependência em relação à ciência e à tecnologia, e levando, do ponto de vista ideológico, à autonomização da ação racional com relação a fins e ao desaparecimento da diferença entre práxis e técnica.

É exatamente nesse aspecto que Habermas diferencia entre as formas da velha e da nova ideologia. Embora para ele, ambas tenham em comum um aspecto particular, - servem para impedir a tematização do funcionamento social, ao mesmo tempo em que asseguraram a lealdade das massas - diferenciar-se-iam quanto aos seus "critérios de justificação da organização da vida em comum", que correspondem às específicas configurações de regulação normativa das interações sociais em geral (Habermas, 2014, p. 119).

Enquanto para Habermas a velha ideologia manifestava-se através de mecanismos de conquistas e obliterações da consciência ou na pura e simples repressão das massas, a nova ideologia, sustentada pela consciência tecnocrática, "não pode do mesmo modo repousar sobre uma repressão coletiva, como as velhas ideologias faziam" (Habermas, 2014, p. 118), uma vez que se sustenta em formas novas de poder social, notadamente no poder de disposição técnica que a vincula a condições estruturais que concorrem para manter o sistema, não se fundando mais sob bases de exploração e opressão incorrigíveis(Habermas, 2014, p. 118), como aquelas típicas do antagonismo de classe imediatamente subjacente à relação entre capitalistas e trabalhadores assalariados (Habermas, 2014, p. 118). Nas sociedades de capitalismo tardio, altamente racionalizadas, a nova ideologia privatiza as necessidades das massas ao mesmo tempo que as compensa através de políticas de distribuição de compensações sociais. A estabilização do sistema garantir-se-ia, portanto, como componente do próprio sistema, que, assim, se despolitiza e subordina os comportamentos dos indivíduos aos imperativos adaptativos do progresso técnico-científico.

Para Habermas, a consciência tecnocrática feriria "um interesse inerente a uma das duas condições fundamentais de nossa existência cultural: a linguagem ou, mais exatamente, a forma de socialização e individuação determinada pela comunicação linguística" (Habermas, 2014, p. 119, grifos nossos). O interesse, ao qual Habermas se refere aqui, tem seu vínculo tanto na "manutenção de uma intersubjetividade do entendimento, quanto no estabelecimento de uma comunicação livre de dominação" (Habermas, 2014, p. 119). Ele desconstrói, assim, a ideia de que o interesse transportaria conteúdos contrários à produção da verdade científica e argumenta que não é este que ameaça "nossas exigências fundamentais como espécie", pois o oposto da ideologia não seria a verdade - como parecia 
levar a supor aquela noção obsoleta de ideologia enquanto falsa consciência - mas justamente uma razão interessada e crítica.

Eagleton (1997, p. 118) argumenta que a ideologia, nos termos habermasianos, se tornou um modo de "comunicação sistematicamente distorcida pelo poder - um discurso que se tornou um meio de dominação e que serve para legitimar relações de forças organizadas”. Enquanto Konder (2002) situa a relevância da abordagem de Habermas para a crítica contemporânea à ideologia, uma vez que contribui para o debate acerca da ciência que se tecnicizou e que, ao deixar de ter "virtudes educativas [...] passa a ser uma ciência que não se dispõe mais a refletir criticamente sobre si mesma” (Konder, 2002, p. 131), Axel Honneth (1989), por sua vez, pondera que, com a autonomização do mundo sistêmico, Habermas teria pensado a integração econômica e estatal como processo que se desenvolveria acima dos mecanismos típicos do entendimento intersubjetivo característico do mundo da vida e esvaziado a vida prática de qualquer substância normativa. Isso o teria impedido de introduzir a categoria do poder em sua teoria da ação comunicativa, somente o fazendo na perspectiva do mundo sistêmico, técnico-científico, ou seja, na perspectiva da teoria dos sistemas que ele integrou às suas abordagens (Honneth, 1989, p. 371).

Para Honneth o problema acima exposto deve ser creditado também ao fato de que Habermas tende a considerar a atividade do trabalho somente como uma forma de ação instrumental, fazendo abstração dos elementos expressivos presentes mesmo no jovem Marx, que criticou o trabalho apenas na sua forma alienada. É a interpretação equivocada feita por Habermas da obra de Marx que o teria levado a inscrever a esfera da interação em sua razão comunicativa e, com isso, a diferenciar entre o mundo sistêmico e o mundo da vida, deixando o último figurar apenas como um espaço potencialmente aberto à colonização pelo primeiro. É justamente no espaço da interação simbolicamente mediada que o processo comunicativo deve se fundar como atividade livre de toda distorção, ou seja, é no contexto de relações assimétricas reais entre os agentes comunicativos que buscam o entendimento intersubjetivo que Habermas postula uma situação ideal de fala, sem que as condições estruturais se alterem para permitir o acesso de todos aos espaços públicos da agência discursiva.

\section{HONNETH E O RECONHECIMENTO IDEOLÓGICO}

Em Axel Honneth a Teoria do reconhecimento vem se consolidando como um importante instrumento para a normatização de esforços políticos progressistas (inscritos principalmente nas pautas e agendas dos movimentos e organizações 
sociais), mas surgem também dúvidas quanto ao seu potencial substantivamente crítico (Fraser, 2006; Mattos, 2012). Seus postulados escamoteariam "assimetrias econômicas, engessando e essencializando identidades, ou até mesmo alimentando a lógica que embasa a opressão" (Mendonça, Porto, 2017, p. 145).

Não alheio a esse debate - ou talvez em decorrência mesmo de seus efeitos sobre a sua prática teórica -, Honneth se viu premido a responder à questão primordial de ser supostamente a Teoria do reconhecimento um mero ato cognitivo, questão levantada por Nancy Fraser, e justificar-se em relação ao fato de que o reconhecimento não pode se restringir a ser expressão de uma mera gramática moral dos conflitos sociais, mas deve colocar-se de modo ativo contra as desigualdades socioeconômicas institucionalizadas. Ressalte-se que em sua obra de fundação da Teoria do reconhecimento, Luta por Reconhecimento [1992], Honneth não confere à dimensão material e distributiva do reconhecimento qualquer centralidade, embora se esforce por superar as limitações idealistas da filosofia hegeliana, como salienta Soares do Bem (2020, p. 255), ao fazer um salto gigantesco das obras de Hegel para a psicologia social de George Mead, justamente com o objetivo de oferecer um quadro referencial pós-metafísico para a ideia hegeliana do reconhecimento.

Com relação à ideologia, um grande silêncio paira também sobre as ricas incursões de reconstrução normativa realizadas por Honneth nos campos disciplinares por ele privilegiados nesta obra de fundação. Ao ser reiteradamente inquirido sobre as formas não éticas e não defensáveis de reconhecimento, que reproduzem posições de subordinação estrutural de determinados grupos sociais em contextos discursivos e práticos com a valorização formal de suas propriedades e capacidades (como o reconhecimento de mulheres enquanto boas donas de casa e etc.), Honneth é provocado a refletir sobre o caráter polissêmico do reconhecimento e a considerar que ele não somente carrega a promessa de autorrealização individual e social, mas pode também ser capturado por uma lógica alheia ao seu conteúdo normativo.

No artigo Reconhecimento como ideologia: sobre a correlação entre moral e poder, Honneth (2014) reporta-se à concepção de ideologia em Louis Althusser, que põe (supostamente) em dúvida o potencial crítico da Teoria do reconhecimento, como ele a concebe.Em defesa do potencial crítico do reconhecimento, Honneth argumenta que ele é formalmente crítico em relação à privação, pois esta provoca sentimentos de humilhação e aviltamento da dignidade humana, e argumenta que as práticas legítimas de reconhecimento não são funcionais à dominação. Quatro premissas são utilizadas pelo autor para delinear a ideia do reconhecimento, aqui 
enunciadas: a primeira refere-se às afirmações das qualidades positivas de sujeitos e grupos sociais; a segunda caracteriza-se por comportamentos de reconhecimento expressos em atitudes eficazes no plano da ação; a terceira expressa-se no reconhecimento positivado em formas das relações intersubjetivas; e, por último, o reconhecimento como expressão genérica inscrita em três esferas de interação social - o amor, o respeito jurídico e a estima social.

Já as ideologias de reconhecimento, para Honneth, afirmam-se a partir de sistemas de valores que bloqueiam o desenvolvimento da autorrealização individual. Por esta razão, ele é enfático ao afirmar que as "ideologias que, por força do reconhecimento social podem ser eficazes, não deveriam contribuir para a exclusão dos grupos de pessoas a que elas se destinam, mas, ao contrário, teriam de contribuir para sua integração" (Honneth, 2014, p. 109). Honneth arrola alguns exemplos que se apresentam como formas de valorização opostas à autorrealização ("o papel da boa dona de casa", "o bom escravo" e "o soldado heróico") e concebe que o reconhecimento social pode degradar-se em formas ideológicas de reconhecimento, de modo a engendrar atitudes e comportamentos conformistas.

A questão temporal mostra-se como um dos primeiros desafios a orientar esta discussão. Pois as transformações históricas, que configuram modos distintos de expectativas em relação aos papéis de indivíduos e grupos sociais, imporiam marcos diferenciais na definição de critérios valorativos, conforme os exemplos citados por Honneth (2014). O autor procura entender (citando um dos exemplos acima), "Por que o escravo não poderia, por meio da experiência de ter sua própria sujeição estimada por seu senhor branco, alcançar uma forma de sentimento de autoestima que o ajudasse a alcançar um certo grau de autonomia interior?” (Honneth, 2014, p. 103). Ora, com tal pergunta, Honneth agrega um problema a mais em sua reflexão, pois ao valorizar a perspectiva subjetiva do escravo em ter a sua sujeição estimada pelo senhor e, com isso, poder alcançar um certo grau de autonomia interior, acaba por deixar fora do domínio da avaliação moral a exclusão objetiva deste no interior de um sistema que sequer reconhece a sua humanidade.

Para Honneth (2014), o reconhecimento ideológico desafia uma própria compreensão negativa da ideologia, já que se afirma enquanto uma enunciação positiva. O problema para Honneth estaria na distinção entre formas ideológicas de reconhecimento moralmente justificadas. Considerada a dificuldade evidente de distinguir entre as formas de reconhecimento ideológicas das formas de reconhecimento "legítimas", partindo de suas reflexões sobre Althusser, Honneth busca evidenciar como as formas ideológicas de reconhecimento são apenas raramente irracionais - aspecto, aliás, que está em franca conformidade com as posições de 
Althusser (Cf. Althusser, 1985; 2008). Mas saliente-se: o reconhecimento ideológico em Althusser tem o objetivo de explicitar os mecanismos ideológicos a partir dos quais as relações de subordinação são reproduzidas pelos sujeitos interpelados, que cedem aos apelos da ideologia e, ao reconhecerem serem eles os interpelados, se colocam - com motivações próprias (selbsttätig), e não movidos por forças que os assaltam como se fossem meros executores de operações mecânicas - ao lado das relações de dominação.

Uma leitura atenta da interpretação honnethiana de Althusser demonstra que ele negligenciou justamente a contribuição mais importante do pensador francês, não reconhecendo o fato de ele ter aberto um lastro fundamental para lançar por terra dois pressupostos que haviam, até então, feito uma longa carreira na teoria social desde meados do século XIX: o primeiro pressuposto tem relação imediata com a insustentável e idealista noção de ideologia como expressão de um mero sistema de ideias sobrepostas às atividades prático-materiais dos homens. Ora, com a sua crítica dos Aparelhos Ideológicos de Estado Althusser (2008) demonstrou que o campo ideológico não é produto de mera representação, mas se presentifica em "espaços institucionais de circulação e reprodução ideológica, permitindo captar a sua dimensão material” (Lima Santos, 2011, p. 71).

Feitas essas considerações, podemos passar agora a outro aspecto negligenciado por Honneth em relação a Althusser. Com efeito, o que Althusser quis demonstrar foi também a insustentabilidade da noção de falsa consciência ao argumentar que os indivíduos não são meras vítimas da ideologia, mas que a ideologia, pelo contrário, os constitui enquanto sujeitos e que é enquanto sujeitos que estes se subordinam às interpelações da ideologia, tornando-se atores do processo de reprodução ideológica. Com isso, Althusser permitiu colocar no centro da reprodução ideológica o problema da responsabilidade individual ou coletiva ao invés de relegá-la a mecanismos cegos e opacos que tendem a repassar a responsabilidade a instâncias situadas sempre além dos sujeitos.

Apesar das críticas endereçadas a Honneth, seu texto de crítica a Althusser, como salientam Soares do Bem e Barreto Júnior (2018, p. 9), "traz uma importante contribuição no sentido de aprofundar uma discussão sobre os significados do reconhecimento" e, com isso, estabelecer critérios mais precisos de avaliação dos horizontes de sua própria teoria. Mas a abordagem da ideologia, como um campo de reflexão consolidado nas ciências sociais desde o século XIX, só poderá ser satisfatoriamente realizada por Honneth - tão sistemático em todos as demais vertentes de suas abordagens - se ele passar a considerá-la um tema privilegiado de sua produção teórica e deixar de tratá-la como categoria dependente, residual, 
que somente é por ele mobilizada quando os fundamentos de sua teoria do reconhecimento se veem ameaçados. É a esta dificuldade que se refere Almeida (2021) em sua dissertação sobre o reconhecimento ideológico em Axel Honneth, quando observa que os autores que tratam a ideologia de modo sistemático não recorrem a ele "quando se referem a qualquer problemática que envolva uma crítica da ideologia" (Almeida, 2021, p. 13), considerando-o "apenas (...) um promissor representante da terceira geração da Teoria Crítica frankfurtiana” (Almeida, 2021, p. 13). Pois buscar em Honneth contribuições substantivas sobre a ideologia, quando o interesse deste centra-se fortemente no desenvolvimento de sua concepção normativa de reconhecimento intersubjetivo, seria incorrer no mesmo equívoco de Honneth de reclamar a ausência de um reconhecimento eticamente defensável em um autor, como Althusser, cujo interesse centra-se única e exclusivamente na problemática da reprodução ideológica.

\section{CONSIDERAÇÕES FINAIS}

Demonstramos como o conceito de ideologia se configura nos sistemas teóricos de representantes da Teoria Crítica, da primeira à terceira geração de pensadores. Evidenciou-se que a crítica da ideologia não apenas configurou diferentes versões da Teoria Crítica, mas também foi subsidiária do próprio movimento das ideias no sentido de se renovar em relação às dinâmicas históricas e estruturais e fornecer diagnósticos de tempo determinados. Tais diagnósticos explicitam a relação inextricável entre a teoria social e a história, e, no caso de nossa investigação, abarca o período que se inicia nos anos 1930 e progride até os nossos dias, permitindo colocar em relevo o impacto das ideias dos pensadores do Instituto de Pesquisa Social ao longo de quase 100 anos de produções teóricas multifacetadas, que poderiam ser narradas, como salientam Bittlingmayer, Demirovic e Bauer (2011, p. 192), como parte de um romance familiar com seus típicos rituais de heranças e continuidades, mas também de combates e dissensos entre as gerações.

Demonstramos que o movimento das teorias sobre a ideologia mantém relação estreita com os contextos históricos, também mutantes, e que as verdades sobre elas estão, portanto, intimamente imbricadas no núcleo histórico que as engendraram. Em Adorno e Horkheimer, demonstramos como a "boa razão" celebrada pelo esclarecimento, enquanto portadora dos ideais universais capazes de realizar as promessas de fazer dos homens seres livres, iguais e fraternos, degradou-se em razão coadjuvante das estratégias de autoconservação, dando lugar a uma "calamidade triunfal" (Adorno, Horkheimer, 1985, p. 19) que enuncia o enfraquecimento, 
senão o aniquilamento dos indivíduos, frente a forças cada vez mais heterônomas regidas por mecanismos ideológicos implacáveis.

Com a produção teórica de Habermas pudemos demonstrar como ele procura se esquivar do diagnóstico sombrio de Adorno e Horkheimer e desenvolver a razão comunicativa, cuja contribuição consiste em considerar como não esgotados os potenciais emancipatórios da modernidade e em evidenciar a existência de fontes intactas de racionalidade inscritas na tradição do estado de direito democrático, em oposição à ideia de um mundo "totalmente" administrado, que tanto marcou o pensamento de Adorno e Horkheimer (Cf. Beer, Trienekens, 2011, p. 288), de modo a encontrar uma saída prática para o projeto do esclarecimento, que, na perspectiva de Adorno e Horkheimer, ter-se-ia maculado por uma falha imanente e degradada em razão instrumental. No entanto, o caráter destrutivo da (velha e da nova) ideologia, no sentido de potencializar riscos relacionados à perda da autonomia, não é absolutamente negligenciado por Habermas, apesar das críticas que dirige a Adorno e Horkheimer. O que se altera em Habermas é que nele as intuições morais podem ser racionalmente legitimadas, mesmo no contexto de ameaças persistentes de colonização do mundo da vida pelo mundo sistêmico (Beer, Trienekens, 2011, p. 288). Mas isso não impediu que Habermas tenha recebido

críticas consistentes e convincentes advindas de pensadores situados dentro e fora da Teoria Crítica.

Com relação a Axel Honneth, demonstramos que ele, entre os demais membros da Teoria Crítica, é o que menos situou a crítica sistemática da ideologia como uma tarefa de sua teorização. Por esta razão, a ideologia só pode ser tratada por ele nos contextos tangenciais a que reserva os desvios da "boa normatividade". Ainda assim, tanto Honneth como os demais autores aqui abordados têm em comum o fato de refletirem criticamente sobre o avanço da racionalidade cega que tem dominado as sociedades modernas e contemporâneas, e que ameaça a qualidade da vida humana em seu conjunto.Além de formularem concepções para a emancipação, a autonomia e o reconhecimento de indivíduos e grupos sociais - uns com mais, outros com menos sucesso.

\section{REFERÊNCIAS BIBLIOGRÁFICAS}

ADORNO, T. W.; HORKHEIMER, M (1985). Dialética do esclarecimento. Rio de Janeiro: Jorge Zahar.

ALMEIDA, Josielice dos Santos (2021). O estatuto do reconhecimento e o reconhecimento ideológico na Teoria Crítica de Axel Honneth. Dissertação de Mestrado. Programa 
de Pós-Graduação em Sociologia - PPGS. 108f. Maceió: Universidade Federal de Alagoas - UFAL.

ALTHUSSER, L. (1985). Aparelhos ideológicos de Estado. Tradução de Walter José Evangelista e Maria Laura Viveiros de Castro. 2. ed. São Paulo: Graal.

ALTHUSSER, L. (2008). "A propósito da ideologia”. In. ALTHUSSER, L. Sobre a reprodução. Rio de Janeiro: Editora Vozes, p. 193-228.

ALWAY, J. (1995). Critical Theory and political possibilities. Conceptions of emancipatory politics in the works of Horkheimer, Adorno, Marcuse, and Habermas. London: Greenwood Press.

BENHABIB, Sheyla (1996). “A crítica da razão instrumental”. In: ZIZEK, Slavoj (org.). Um mapa da ideologia. Tradução de Vera Ribeiro. Rio de Janeiro: Contraponto, p. 71-96. BEER, R.; TRIENEKENS, B. (2011). “Normativitätbei Jürgen Habermas”. In: AHRENS, J.; BEER, R.; BITTLINGMAYER, U. H. (Hrsg.). Normativität. Über die Hintergründe sozialwissenschaftlicher Theoriebildung. Wiesbaden: VS Verlag, p. 287-311.

BITTLINGMAYER, U. H.; DEMIROVIC, A.; BAUER, U. (2011). "Normativität in der Kritischen Theorie”. In: AHRENS, J.; BEER, R.; BITTLINGMAYER, U. H. (Hrsg.). Normativität. Über die Hintergründe Sozialwissenschaftlicher Theoriebildung. Wiesbaden: VS Verlag, p. 189-220.

CHIARELLO, Maurício G. (2001). Das lágrimas das coisas- estudo sobre o conceito de natureza em Max Horkheimer. São Paulo: Editora da Unicamp/ FAPESP.

EAGLETON, Terry (1997). Ideologia: uma introdução. São Paulo: Editora da Universidade Estadual Paulista, Editora Boitempo.

FRASER, Nancy; HONNETH, Axel (2006). ¿Redistribución o reconocimiento? Un debate político-filosófico. Madrid: Morata.

HABERMAS, Jürgen (2014). Técnica e ciência como "ideologia”. Tradução de Felipe Gonçalves Silva. São Paulo: Editora Unesp.

HONNETH, Axel (1989). Kritik der macht. Frankfurt am Main: Suhrkamp Verlag.

HONNETH, Axel (2014). Reconhecimento como ideologia: sobre a correlação entre moral e poder. Revista Fevereiro. Política. Teoria. Cultura, n. 7, tradução de Ricardo Crissiuma, p. 100-117. http://www.revistafevereiro.com/pdf/RevistaFevereiro7. pdf(acesso em 20/09/2017).

KELLNER, D. (1989). Critical Theory, Marxism and Modernity. Baltimore: Johns Hopkins University Press.

KONDER, Leandro (2002). A questão da ideologia. São Paulo: Cia. das Letras.

LIMA SANTOS, A. A. (2011). A representação dos males na Igreja Universal do Reino de Deus. Uma abordagem sobre a construção de inimigos. Dissertação de Mestrado. 
Programa de Pós-Graduação em Sociologia - PPGS. 112f. Maceió: Universidade Federal de Alagoas - UFAL, p. 56-78.

MATTOS, Patrícia (2012). "O desafio da teoria do reconhecimento: a distinção entre as formas ideológicas e as formas éticas de reconhecimento social”. In: MACIEL, Tanias B; D’Avila NETO, M. I; ANDRADE, Regina G. N. (Orgs.). Fronteira e diversidade culturais no século XXI: desafios para o reconhecimento no espaço global. Rio de Janeiro: FAPEJE.

MENDONÇA, Ricardo F.; PORTO, Nathália F. F. (2017). Reconhecimento ideológico: Uma reinterpretação do legado de Gilberto Freyre sob a ótica da Teoria do Reconhecimento. DADOS - Revista de Ciências Sociais, v. 6o, n. 1, p. 145-172. http://www.scielo.br/ pdf/dados/v6on1/oo11-5258-dados-60-1-0145.pdf (acesso em 15/o8/ 2017).

NOBRE, Marcos (2009). “Apresentação”. In: HONNETH, Axel. Luta por reconhecimento

- A gramática moral dos conflitos sociais. São Paulo: Editora 34, p. 07-19.

SINNERBRINK, Robert (2017). "Modernidade, intersubjetividade e reconhecimento: Habermas e Honneth”. In: SINNERBRINK, Robert.Hegelianismo. Petrópolis, Rio de Janeiro: Vozes, p. 149-178.

SOARES DO BEM, Arim; BARRETO JUNIOR, N. G. (2018). "A ideologia em Adorno/ Horkheimer e o reconhecimento enquanto ideologia em Axel Honneth”. In: Relatório Final Pibic 2017-2018. Manuscrito. Maceió: Universidade Federal de Alagoas - UFAL, p. 1-14.

SOARES DO BEM, Arim. (1986). Comunicação de massa: do mito à prática política. Revista Comunicações e Artes, ano 11, n. 17, p. 187-192.

SOARES DO BEM, Arim (1988). Telenovela e Doméstica: da catarse ao distanciamento. Dissertação de Mestrado. Escola de Comunicações e Artes. 273f. São Paulo: Universidade de São Paulo, p. 1-273.

SOARES DO BEM, Arim. (1992). Brasilianische Hausangestellte und Telenovela: ideologische Reproduktion und Widerstand. Revista Communicatio Socialis Zeitschrift für Publizistik in Kirche und Welt, Nr. 4. Paderborn: Verlag Ferdinand Shöningh, p. 352-367.

SOARES DO BEM, Arim (2013). Paradoxos da diferença: etnicidade, inimificação e reconhecimento (Alemanha-Brasil). Curitiba: Editora Appris.

SOARES DO BEM, Arim (2020). O lugar da comunidade na teoria do reconhecimento de Axel Honneth. Revista Contemporânea - Revista de Sociologia da UFSCar, v. 10, p. 249-272.

WIGGERSHAUS, R. A. (2002). Escola de Frankfurt. História, desenvolvimento teórico, significação política. Rio de Janeiro: Difel.

Recebido: 27/09/2020 | Aprovado: 15/09/2021 